\title{
Identificación Rápida del Agente Etiológico Mediante Prueba de Aglutinación de Látex en Meningitis Bacteriana Aguda
}

\author{
Dra. Marisa del Valle M. ${ }^{1}$; Dra. Sonia Hannig K. ${ }^{1}$; Dr. Pablo Vial C. ${ }^{1}$; \\ Dr. Francisco Montiel A. 2 ; Dr. Mario Cerda S. 3
}

\begin{abstract}
A prospective study was done on all patients hospitalized in the Pcdiatric Wards of a general hospital at South-East Santiago between December 1983 and July 1984, in whom the diagnosis of acute bacterial meningitis was done. Cytological and chemical work-up, Gram stain, cultures and Latex Aglutination test (LAT) of cerebro-spinal fluid (CSF) plus two blood cultures were carried out on each patient, 21 patients, 13 males, with mean age 10 months were studied. The LAT was positive in 20 patients (95\%) and the Gram stain revealed the presence of bacteriae in 17 patients $(81 \%) ;=0.88$. The CSF cultures were positive in 10 patients $(48 \%)$, in 8 they were related with positive LAT and in 9 with Gram stain. Only one blood culture gave positive results. The advantages of LAT afe it's simplicity, quickness and unexpensiveness in the diagnosis of acute bacterial meningitis. Although it does not replace bacterial culture, LAT may be a useful aid in the initial evaluation, or in the search of additional clues on the etiology of individual cases and it may also afford an approach to the cause of meningitis in patients who have previously been treated with antibiotics.

(Key words: Bacterial meningitis. Causal agent identitication. Latex Aglutination test).
\end{abstract}

La meningitis bacteriana aguda es una enfermedad grave con alta mortalidad y secuelas importantes, directamente relacionadas con el retraso en el diagnóstico y tratamiento, por lo que la identificación del agente etjológico en el menor tiempo posible es de gran importancia ${ }^{1}$.

El diagnóstico bacteriológico se basa actualmente en la tinción de Gram del líquido cefalo. rraquídeo (LCR) y el cultivo bacteriano. El primer método tiene una positividad de 60 a $80 \%$ en las meningitis bacterianas por $\mathbf{H}$. influenzae, $\mathrm{S}$. pneumoniae y $\mathrm{N}$. meningitidis $1-2$. Pueden producirse falsos negativos en aquellos pacientes cuyo LCR contenga menos de 1.000 microorganismos

1. Becados. Depto. de Pediatría. Universidad Católica de Chile y Hospital Sótero del Río. Santiago.

2. Laboratorio de Microbiología, CEDIUC. Universidad Católica de Chile.

3. Undad de Cuidado Intensivo. Hospital Sótero del Río. Santiago. por mi. y falsos positivos por contaminación de éste durante el procedimiento ${ }^{2-3}$.

El cultivo bacteriano es el único medio para hacer el diagnóstico etiológico de certeza, demora 48 a 72 horas y en nuestro medio tiene un porcentaje de recuperación entre 30 y $80 \% 4-5$. Los dos métodos mencionados, rara vez proporcionan un resultado positivo cuando se ha admi. nistrado un tratamiento antibiótico previo a la toma de muestra ${ }^{6 \cdot 7}$.

La prueba de aglutinación de Látex se ha usado con buen éxito en el diagnóstico de los gérmenes que con mayor frecuencia producen meningitis bacteriana aguda en niños ${ }^{8}-9-10$. 11. Se basa en la detección de antígenos bacteria. nos específicos, generalmente polisacáridos de superficie (cápsula o capa externa de la pared) liberados por las bacterias durante su desarrollo, que persisten en los líquidos biológicos aún cuando las bacterias no son detectables. Particulas de látex sensibilizadas por anticuerpos especi. 
ficos provocan, al contactar con los antigenos correspondientes, una reacción de aglutinación.

Si bien la prueba no reemplaza al cultivo bacteriano puede ser una importante guía en el diagnóstico inicial y una forma de identificar la etiologia en pacientes que hayan recibido tratamiento antibiótico previo.

El objetivo de este estudio fue evaluar la utilidad de la prueba de aglutinación de Látex en el diagnóstico de pacientes con meningitis bacte. riana aguda y analizar su correlación con la tinción de Gram y el cultivo de LCR.

\section{MATERLAL Y METODO}

Se estudiaron en forma prospectiva, todos los pacientes ingresados con el diagnóstico de meningitis aguda al Servicio de Pediatria del Hospital Sótero del Río en el período comprendido entre el 10 de Diciembre de 1983 y el 31 de Julio de 1984.

El criterio empleado para el diagnóstico de meningitis bacteriana aguda incluyo la existencia de síndrome infeccioso, compromiso neurológico con o sin signos meníngeos y alteraciones del LCR (Glucosa inferior al $50 \%$ de la glicemia o menor de $40 \mathrm{mg} \%$, Proteinas superior a $100 \mathrm{mg} \%$ y Células entre 200 y 20.000 por cc.).

En todos los pacientes se tomaron las muestras de LCR al ingreso, realizándose estudio citológico, citoquímico, tinción de Gram. cultivo, prueba de Látex y dos hemocultivos. La prueba de aglutinación de Látex fue realizada por el residente de turno usando Slidex MéningiteKit, equipo que contiene los reactivos necesarios para el diagnóstico rápido de las meningitis bacterianas por $\mathrm{N}$. meningitidis $A$ y $\mathrm{C}, \mathrm{H}$. influenzae, tipo B, S. pneumoniae ( 83 serotipos).

La reacción se efectúa directamente sobre el LCR previamente centrifugado, depositando una gota de éste y una gota de cada uno de los cuatro Látex sensibilizados. Si el LCR contiene el antígeno soluble correspondiente a una concentración superior al umbral de sensibilidad (N. meningitidis $\mathrm{A}$ y $\mathrm{C}$ y $\mathrm{H}$. influenzae de 0.0255 , $\mu \mathrm{g} / \mathrm{ml}$, S. pneumoniae $0.1-0.5 \mu \mathrm{g} / \mathrm{ml}$ ), se produce una aglutinación de las partículas de Látex visible en menos de dos minutos. Un testigo positivo permite verificar periódicamente la actividad de los látex sensibjlizados. Este equipo permite procesar 50 muestras.

\section{RESULTADOS}

Durante este período ingresaron al Servicio de Pediatria del Hospital Sótero del Río veintiún pacientes con diagnóstico de meningitis bacteria- na aguda, trece de sexo masculino (62\%) y ocho de sexo femenino (38\%). El rango de edad fluctuó entre 3 meses y 3 años 4 meses ( $\bar{x} 10$ meses).

Catorce niños eran eutróficos $(66,6 \%)$, dos tenían desnutrición calórico-proteica grado I $(9,5 \%)$ y tres desnutrición calórico-proteica grado II $(14,3 \%)$, según tablas de Sempé. En dos pacientes no se consignó el peso por su gravedad al ingresar. Siete niños habían recibido tratamiento antibiótico previo, cinco Penicilina benzatina por sospecha de Bronconeumonia, uno Trimeto. prin-Sulfametoxasol por Bronquitis aguda $y$ otro Cloxacilina y Cloramfenicol por Bronconeumonia post Sarampión.

La prueba de aglutinación de látex fue positiva en veinte pacientes $(95,2 \%)$ y negativa en uno $(4,8 \%)$. De las reacciones positivas, once correspondieron a $\mathrm{H}$. influenzae tipo $\mathrm{b}(52,3 \%)$, siete a $S$. pneumoniae $(33,3 \%)$ tres de estas calificadas como "débilmente positivas", una a todos los gérmenes $(4,8 \%)$ y una a $\mathrm{N}$. meningitidis $\mathrm{A}$ y $\mathrm{C}$ $(4,8 \%)$. En este último caso se repitió la prueba resultando positiva a N. Meningitidis A.

La tinción de Gram del LCR reveló gérmenes en diecisiete pacientes ( $81 \%$ ), quince de éstos en concordancia con la prueba de Látex ( $88 \%$ ).

Los cultivos de LCR resultaron positiyos en diez pacientes $(47,7 \%)$, ocho con $H$. influenzae $y$ dos con S. pneumoniae; tres habian recibido tratamiento antibiótico previo. Once pacientes $(52,5 \%)$ tuvieron cultivos negativos, cuatro ha. bían recibido antibióticos antes de ingresar. No encontramos diferencias significativas en la positividad de los cultivos al comparar los niños que habían recibido tratamiento antibiótico previo con los que no lo habían recibido.

Considerando al grupo de pacientes cuyo cut tivo fue positivo, hubo concordancia con la prueba de aglutinación de Látex en ocho (80\%), con la tinción de Gram en nueve $(90 \%)$ y con anbos en ocho pacientes (80\%).

En dos pacientes la prueba de aglutinación de Látex fue falsamente positiva y con reacción débilmente positiva para $S$. pneumoniae en circunstancias que en el cultivo se aisló $\mathrm{H}$. influezae.

Parece importante señalar que no hubo falsos negativos.

Finalmente, encontramos sólo un hemocultivo positivo $(4,7 \%)$, que fue concordante con la prueba de aglutinación de Látex; mientras el cultivo de LCR resultó negativo.

\section{DISCUSION}

En el grupo estudiado obtuvimos una alta positividad en la prueba de aglutinación de Látex y tinción de Gram $(95,2 \%$ y $81 \%$ respectivamen- 
te), con una buena concordancia entre ambos métođos $(88 \%)$.

Los cultivos de LCR fueron positivos en un bajo número de pacientes $(47,7 \%)$ de acuerdo a lo comunicado por otros autores ${ }^{5}$. Llama la atención la bajísima positividad de los hemocultivos $(4,7 \%)$; atribuímos esto en parte, a problemas de técnicas, ya que no contamos con los medios para efectuar la siembra de muestras en forma oportuna.

En el grupo de pacientes con cultivos de LCR positivos, encontramos una buena correlación con la prueba de aglutinación de Látex y la tinción de Gram. Las dos pruebas falsas positivas, pueden corresponder a mala interpretación por falta de experiencia en la lectura de la reacción. No se encontraron falsos negativos.

No fue posible realizar análisis estadístico de sersibilidad y especificidad del método por el escaso número de pacientes y por no disponer de un grupo control.

El método tiene las ventajas de ser simple, rápido, no necesita bacterias viables para dar resultado positivo y es de bajo costo ( $\$ 700$ por muestra).

Para una correcta interpretación, la reacción de Látex debe ser hecha por un observador entrenado y su lectura con luz adecuada, sobre fondo negro y exactamente dos minutos después de mezclar la muestra con los Látex sensibilizados.

Si bien, esta prueba no reemplaza al cultivo bacteriano, puede ser de utilidad para guiar el diagnóstico inicial, permitiendo una orientación etiológica rápida y en cierto modo también pronóstica, importante desde el punto de vista epidemiológico para adoptar las medidas necesarias y para diferenciar si existe duda entre etiologías bacteriana y viral.

Como la reacción no requiere de la presencia de bacterias viables puede ser útil para ayudar a identificar la etiologia en pacientes que hayan recibido tratamiento antibiótico previo.

\section{RESUMEN}

Se estudiaron en forma prospectiva todos los pacientes ingresados al Servicio de Pediatría del Hospital Sótero del Río con el diagnóstico de meningitis bacteriana aguda entre Diciembre de 1983 y Julio de 1984. En todos los pacientes se hizo estudio citoquimico, tinción de Gram, cultivo, prueba de aglutinación de Látex de LCR y dos hemocultivos. El total de pacientes estudia- dos fue veintiuno, trece del sexo masculino $y$ ocho del femenino, con un promedio de edad de 10 meses. La prueba de aglutinación de Látex fue positiva en veinte pacientes $(95,2 \%)$, la tinción de Gram mostró gérmenes en diecisiete niños $(81 \%)$ y la concordancia entre ambos métodos fue de $88 \%$. Los cultivos de LCR fueron positivos en diez pacientes $(47,7 \%)$, ocho concordantes con la prueba de Látex y nueve con la tinción de Gram. Sólo hubo un hemocultivo positivo y fue concordante con la reacción de Látex. La prueba de aglutinación de Látex tiene las ventajas de ser un método simple, rápido y de bajo costo. Si bien no reemplaza al cultivo bacteriano, permite una orientación etiológica rápida y puede ayudar a identificar el agente causal en pacientes que hayan recibido tratamiento antibiótico previo.

\section{REFERENCIAS}

1. Guiscufre H., Marrufo C. Trejo I, Ramirez M., Gonzalez A., Muñoz O.: Meningoencetalitis por $\mathrm{H}$. influenzae y St. pneumoniae: Diagnóstico rápjdo por coaglutinación en líquido cefalorraquídeo. Bol. Med. Hosp. Infant. Mex, 41: 262, 1980.

2. Wiliam J., Martin Ph. D.: Rapid and reliable techniques for the laboratory detection of bacterial me ningitis. Am. J. Med. 28: 119, 1983.

3. Musher D,M, Schell R.: False - Positive Gram stains of cerebrospinal fluid. Ann. Intern. Med. 79 $603,1973$.

4. Juliet $C$, Radriguez G., Martina, Burgos O.: Meningitis bacteriana en el nifro: Experiencia con 441 casos. Rev, Med. Chil. 111, 7: 690, 1983.

5. Gallo A. Vivimi $T$.: Factores pronósticos de la meningitis purulenta en el lactante. Congreso de Pediatría de 1981.

6. Jarvis C.W., Sarena $K, M$.: Does prior antibiotic hamper the diagnosis of bacterial meningitis? Clin. Ped. 11: 201, 1972.

7. Winklestein J.A.: The influence of partial treatment with penicillin on the diagnosis of bacterial meningitis. J. Pediatr. 77: $619,1970$.

8. Kaplan $S$., Feigin $R$.: Rapid indentification of the invading microorganism. Pediatr. Clin. North Am. 4: 809,1980 .

9. Whittle H.C., Tugwell P., Egler L., Greenwood B.: Rapid bacteriological diagnosis of pyogenic meningitis by latex aglutination. Lancet 14: 619, 1974.

10. Koldor $J$., A sznowwies R., Buist D.: Latex aglutination in diagnosis of bacterial infections, with special reference to patients with meningitis and septicemia. Am. J. Clin. Pathol. 68: 284, 1977.

11. Severin W.P.J.: Latex aglutination in the diagnosis of meningococcal meningitis. J. Clin. Pathol. 25: $1.079,1972$.

12. Denis F., Cados M., Diop Mar I., Saulnier M.: Bacterial antigen concentrations in cerebroespinal fluid and prognosis of purulent meningits. Lancet 20: $1.361,1981$. 